\title{
Recém-nascido prematuro: suporte materno domiciliar para o cuidado
}

\author{
Premature newborn: maternal support at home for care \\ Recién-nacido prematuro: apoyo materno domiciliar para el cuidado
}

Fabiane Ferreira Couto', Neide de Souza Praçal"
'Universidade Estadual de Campinas, Centro de Atenção Integral à Saúde da Mulher. Campinas-SP, Brasil.
"Universidade de São Paulo, Escola de Enfermagem, Departamento de Enfermagem Materno-infantil e Psiquiátrica. São Paulo-SP, Brasil.

Submissão 14-12-2010 Aprovação: 17-01-2012

\section{RESUMO}

Este estudo descritivo, com abordagem qualitativa, teve como objetivo identificar o suporte materno, no domicílio, para o cuidado do recém-nascido prematuro egresso de Unidade Neonatal. O estudo, realizado em 2008, entrevistou doze mães residentes no município de Sumaré-SP. Os relatos, gravados, foram tratados pela técnica do Discurso do Sujeito Coletivo (DSC). Os resultados acrescem o conhecimento de enfermagem pela diversidade de recursos que emergiram, e que revelaram a importância da inserção materna na Unidade Neonatal; valorizaram a Cartilha de orientação oferecida pelo serviço; e destacaram a relevância do apoio social para o cuidado do bebê, no domicílio. Recomenda-se a inserção do familiar no plano de enfermagem para a alta do prematuro na Unidade Neonatal.

Descritores: Cuidados de enfermagem; Recém-nascido prematuro; Assistência domiciliária; Educação em saúde.

\section{ABSTRACT}

This is a descriptive study with qualitative approach. The aim was to identify maternal support at home for the care of premature newborns egress of Neonatal Unit. It was conducted in 2008 by interviewing twelve mothers living in Sumaré, São Paulo, Brazil. The recorded reports were treated by the technique of the Collective Subject's Discourse (CSD). The results increase the nursing knowledge by the diversity of resources that have emerged and revealed the importance of integrate the mother in the Neonatal Unit; valued the Guide Book offered by the service, as well as highlighted the relevance of social support for the baby's care at home. It is recommended the inclusion of the family members in nursing plan to preterm infant discharge from the Neonatal Unit.

Key words: Nursing care; Infant; Home nursing; Health education.

\section{RESUMEN}

Este estudio descriptivo, con enfoque cualitativo, tuvo como objetivo identificar el apoyo materno en el domicilio para el cuidado de lo recién nacido prematuro salido de la Unidad Neonatal. Se llevó a cabo en 2008, con entrevistas a doce madres que viven en Sumaré, São Paulo - Brasil. Los resultados acrecen el conocimiento por la diversidad de los recursos que han surgido, reveló la importancia de la integración de la madre en la Unidad Neonatal, valorizó la Cartilla de orientación que ofrece el servicio, así como la importancia del apoyo social para el cuidado del bebé en su casa. Se recomienda la inclusión de la familia en el plan de enfermería para la descarga de el recién nacido prematuro de la Unidad Neonatal.

Palabras clave: Atención de enfermería, Prematuro, Atención Domiciliaria de Salud, Educación en Salud. 


\section{INTRODUÇÃO}

Os avanços científicos e tecnológicos, das últimas décadas, têm contribuído para melhoria na assistência à saúde obstétrica e neonatal. A introdução de novas intervenções, em especial nos berçários de alto risco, trouxe benefícios para a sobrevivência de prematuros de extremo baixo peso, tanto em países desenvolvidos como em desenvolvimento ${ }^{(1)}$.

Evidencia-se que o Brasil tem se esforçado para atender as demandas por atenção à saúde da criança, e em especial do recém-nascido prematuro. Nesse aspecto, compõe o grupo de 191 países que assinaram a Declaração do Milênio, estabelecida pela Organização das Nações Unidas, que tem como meta a melhoria das condições de vida da população mundial até 2015 . Dentre as oito metas estabelecidas pelo programa, a de número quatro visa reduzir a mortalidade de crianças menores de cinco anos. Como compromisso assumido, o país tem traçado políticas de atenção a este segmento com definição de recursos e implantação de programas voltados ao bem-estar das crianças, assim como de suas famílias e da comunidade(2)

Como políticas governamentais de atenção à criança, foram estabelecidas diretrizes de atuação por meio de programas dedicados à Saúde de modo geral, à Humanização do parto, à redução da Mortalidade Materna e Neonatal, à Internação Domiciliar Neonatal, à diminuição da Mortalidade Infantil em regiões específicas, à Atenção Humanizada ao Recém-nascido de Baixo Peso (Método Canguru) e à Iniciativa Hospital Amigo da Criança, com destaque para a promoção de vínculo e apoio ao aleitamento materno.

Ao coordenar as políticas que estabelecem intervenções na realidade social e de saúde do segmento infantil, o Ministério da Saúde define ações dos profissionais para o cumprimento da meta estabelecida pela Declaração do Milênio. No momento, as intervenções demonstram êxito na redução de mortalidade de crianças menores de cinco anos, pois se constata queda de 58\% nos óbitos, no período de 1990 a 2008, nesta faixa etária ${ }^{(2)}$.

Aliada aos recursos tecnológicos e às políticas governamentais, de modo a atender à demanda crescente por necessidades que surgem na prática cotidiana, faz-se necessária e constante a atualização dos profissionais que assistem o recém-nascido prematuro. O desenho da atenção considera que a evolução dessas crianças requer acompanhamento que assegure aos seus pais e familiares prestarem cuidados que favoreçam adequado crescimento e desenvolvimento.

Assim, a atenção prestada ao recém-nascido prematuro, pelos pais, deve ser direcionada tanto em um contexto integral, abrangendo os cuidados corporais, de alimentação e de administração de medicamentos, dentre outros, como no contexto que promova a interação destes pais com seus bebês, o que favorece o vínculo entre ambos.

Dessa forma, é necessário que o ambiente da Unidade de Terapia Intensiva Neonatal (UTIN) seja receptivo e acolhedor, tanto para o bebê como para os pais. Um ambiente pouco receptivo e hostil pode inibir os comportamentos espontâneos e dificultar a ligação afetiva entre a família e o recém-nascido(3).
Os serviços desenham modalidades de assistência que atendam às necessidades de sua clientela, com o propósito de assegurar o desenvolvimento e o crescimento satisfatório do recém-nascido prematuro fora do ambiente hospitalar. A literatura e a observação empírica mostram que as unidades neonatais desenvolvem programas de orientação voltados ao familiar cuidador, preparando-o para a alta hospitalar do recém-nascido prematuro, de modo a favorecer o cuidado que este deve receber no domicílio. Nesse aspecto, a mãe de recém-nascido prematuro vale-se de sua rede de suporte social que a apóia em seu cotidiano e que é utilizada como provedora de auxílio e de conselhos para o cuidado da criança ${ }^{(4)}$.

Esse contexto, associado à alta hospitalar, às fragilidades próprias do recém-nascido prematuro, e à sua inserção no contexto domiciliar motivaram a realização deste estudo que buscou responder a seguinte questão: a mãe de recém-nascido prematuro egresso de Unidade de Terapia Intensiva Neonatal dispõe de auxílio, no domicílio, para cuidar da criança no período imediato à alta hospitalar?

Diante do exposto, este estudo tem como objetivo identificar o suporte materno, no domicílio, para o cuidado do recém-nascido prematuro egresso de unidade neonatal.

\section{MATERIAL E MÉTODO}

Este é um estudo descritivo, com tratamento qualitativo de dados. Foi realizado em um hospital estadual, situado no município de Sumaré, SP. Trata-se de hospital da rede pública de saúde, administrado por uma universidade da rede estadual pública, e que atende por convênio do Sistema Único de Saúde (SUS). É referência para os distritos de saúde do município onde se insere e para cidades próximas. Dentre suas especialidades clínicas, o serviço de neonatologia é composto pela Unidade Neonatal, que compreende a Unidade de Terapia Intensiva Neonatal, e as unidades Semi-Intensiva e Canguru.

A Unidade Neonatal conta, também, com o Grupo de Apoio aos Pais Acompanhantes (GAPA), composto por familiares dos recém-nascidos internados, cujos trabalhos ocorrem por meio de reuniões semanais, momento em que são abordadas as condições dos bebês internados, assim como seus cuidados durante a hospitalização, é realçada a importância da amamentação, e são abordados outros temas emergentes das discussões.

A Unidade Canguru, composta por dois leitos, é utilizada por mães, cujos recém-nascidos encontram-se internados na Unidade Semi-Intensiva e que estão próximos da alta hospitalar. Nela, a mãe recebe orientações sobre o cuidado do fiIho, relacionadas à higiene, à troca de roupas, à alimentação, à administração de medicações, bem como sobre cuidados específicos demandados durante o período de hospitalização. São orientações oferecidas progressivamente à mãe, pelos profissionais de enfermagem que prestam assistência aos recém-nascidos internados. Vale esclarecer que o enfoque dessa unidade não é o favorecimento contínuo do contato pele-a-pele entre mãe-bebê-prematuro, pois se trata de um alojamento materno e a criança não permanece junto à mãe, devendo esta se dirigir às salas de cuidado semi-intensivo para 
prestar-lhe cuidado, sob supervisão e orientação de um profissional de enfermagem.

No hospital campo do estudo, o preparo para a alta hospitalar é um processo contínuo, que tem início na Unidade de Terapia Intensiva Neonatal e se intensifica, posteriormente, na Unidade Semi-Intensiva. As orientações sobre o cuidado do recém-nascido são oferecidas, diariamente, pela Enfermagem. A mãe, geralmente, é o alvo. As intervenções incluem a facilitação do vínculo, com incentivo ao toque e à amamentação.

No processo de alta, entre a saída da Unidade Semi-Intensiva e o domicílio, há uma fase de transição, quando são disponibilizadas à mãe a Unidade Canguru e a Casa de Apoio. Esta compreende uma unidade de alojamento temporário cedida pelo hospital. A mãe do recém-nascido prematuro permanecerá na Casa de Apoio se, eventualmente, não houver vagas disponíveis na Unidade Canguru, que corresponde à fase de capacitação para o cuidado do bebê no período pós alta hospitalar.

A orientação para alta do recém-nascido prematuro, oferecida pelo neonatologista e pela enfermeira da Unidade Neonatal, se complementa com o oferecimento, à mãe, de uma cartilha construída pela Enfermagem do serviço, na qual constam orientações sobre o cuidado com a alimentação e os procedimentos diante da ocorrência de cólicas, bem como orientações sobre questões relacionadas à estimulação para o crescimento e o desenvolvimento, à higiene oronasal e do coto umbilical, à higiene corporal, à troca de fraldas, aos cuidados com as roupas, ao banho de sol e o seguimento para vacinação.

Participaram do estudo doze mães de bebês prematuros egressos das Unidades de Terapia Intensiva e Semi-Intensiva Neonatal do referido hospital. Essas mães foram entrevistadas aproximadamente oito dias após a alta do recém-nascido prematuro da Unidade Neonatal. Cabe ressaltar que, no momento da entrevista, os bebês tinham entre 19 e 90 dias de vida. Destaca-se, ainda, que dez recém-nascidos prematuros permaneceram internados na Unidade de Terapia Intensiva Neonatal por período compreendido entre menos de dez dias até mais de 30 dias, e que, após permanecerem na Unidade de Terapia Intensiva, foram transferidos para a Unidade Semi-Intensiva. A permanência dos doze recém-nascidos nesta unidade ocorreu em período que variou de menos de dez dias até mais de 30 dias.

Por se tratar de pesquisa com abordagem qualitativa, não houve definição prévia do número de participantes do estudo. Assim, a interrupção da coleta de dados e a determinação do total de entrevistadas ocorreram quando os achados tornaram-se repetitivos, o que é chamado de amostragem por saturação teórica ${ }^{(5)}$, indicativo para o encerramento da captação de novos entrevistados.

Para ser incluídas no estudo, as mães atenderam os seguintes critérios: ter tido recém-nascido prematuro com até 36 semanas e 6/7 de idade gestacional ao nascimento, com peso de alta hospitalar entre $1.800 \mathrm{~g}$ a $2.000 \mathrm{~g}$; e ter tido recém-nascido prematuro que permaneceu internado na Unidade Neonatal do hospital, campo do estudo. O tempo de permanência do bebê prematuro na Unidade Neonatal não foi considerado como critério de inclusão, pois independente do período de internação, todas as mães receberam treinamento para o cuidado do filho no domicílio.

A coleta de dados ocorreu no período de julho a outubro de 2008. Ao levar o recém-nascido prematuro de alta, a mãe era orientada a retornar para avaliação no período aproximado de oito dias, ocasião em que era convidada a participar do estudo. Diante de sua concordância, e após assinatura do Termo de Consentimento Livre e Esclarecido, a entrevista gravada era realizada em sala privativa na própria instituição de saúde.

A coleta de dados ocorreu por meio de entrevista com o preenchimento de um roteiro composto por três partes: Parte I - dados de identificação materna; Parte II - dados de identificação do recém-nascido prematuro, com enfoque no nascimento, no período de internação, nas condições relacionadas à alta, e nos encaminhamentos; e Parte III - dados sobre o domicílio do binômio mãe-recém-nascido-prematuro. Os dados das Partes I e II foram obtidos do relatório de alta hospitalar trazidos pela mãe e preenchidos pelo neonatologista e pela enfermeira no momento da alta hospitalar. Os dados que não constavam desse documento foram coletados do prontuário médico do bebê, na Unidade Neonatal.

Vale esclarecer que o peso do recém-nascido foi classificado segundo o preconizado na literatura em baixo peso ao nascer (menos de $2.500 \mathrm{~g}$ ), muito baixo peso (menos de $1.500 \mathrm{~g}$ ) e extremo baixo-peso (menos de $1.000 \mathrm{~g})^{(6)}$.

Após o preenchimento do instrumento, empregou-se a seguinte questão norteadora: "Como tem sido para a senhora cuidar do seu filho em casa?" Quando necessário, utilizaram-se questões complementares relacionadas à higiene, à alimentação e às medicações do recém-nascido, e ao emprego da cartilha recebida no momento da alta hospitalar.

Os dados de identificação foram ordenados e são apresentados de forma descritiva, enquanto que os obtidos com a questão aberta sofreram tratamento segundo o método do Discurso do Sujeito Coletivo (DSC) $)^{(7)}$. O conteúdo dos relatos foi transcrito e sofreu repetidas leituras para melhor compreensão. A seguir, de acordo com o método do DSC, extraiu-se de cada entrevista os elementos que compõem esta estratégia, descritos a seguir:

Expressões-chave: correspondem a trechos selecionados do material de cada relato, que melhor descrevem o seu conteúdo. Neste estudo, foram extraídas as frases dos relatos que atendiam ao objetivo do estudo e que foram consideradas de interesse;

Ideias centrais: descrevem o sentido presente nas expressões-chave extraídas dos depoimentos de cada relato. Após a fase anterior, atribuiu-se sentido a cada frase selecionada;

Discurso do Sujeito Coletivo: é a reunião das expressões-chave extraídas dos depoimentos distintos, que têm ideias centrais de sentido semelhante ou complementar. Com este procedimento, o material obtido dos relatos individuais foi agrupado coletivamente, e redigido na primeira pessoa do singular, como forma de marcar a presença do pensamento coletivo na pessoa de um Sujeito de Discurso Coletivo.

Este estudo atendeu à Resolução 196/96 do Conselho Nacional de Saúde do Ministério da Saúde e foi aprovado pela 
Comissão de Ensino e Pesquisa do Hospital Estadual de Sumaré, e pelo Comitê de Ética em Pesquisa da Faculdade de Ciências Médicas da Universidade Estadual de Campinas, sob o parecer número: 347/2008.

\section{RESULTADOS}

Recorde-se que, no momento da entrevista, os recém-nascidos prematuros tinham idades que variavam entre 19 e 90 dias, o que direcionou ao emprego do termo "bebês prematuros" em substituição a "recém-nascido prematuro", visto que esta expressão não correspondia à totalidade das crianças, pois a maioria estava com mais de 28 dias de vida.

Os resultados serão apresentados na seguinte sequência: caracterização dos participantes e de sua moradia, e vivência da mãe no cuidado do bebê prematuro, no domicílio.

\section{Caracterização materna e do bebê prematuro}

Dentre as 12 mães participantes, quatro tinham até 20 anos de idade, três encontravam-se na faixa etária de 21 a 25 anos; duas tinham entre 26 e 30 anos de idade; e três estavam na faixa etária igual ou superior a 31 anos. Em relação à escolaridade, quatro mães cursaram até o ensino fundamental e oito haviam cursado o ensino médio. Todas as entrevistadas apresentavam alguma renda: quatro referiram renda familiar mensal entre um e meio a dois salários mínimos; e seis citaram dois e meio a três e meio salários mínimos mensais. Uma participante relatou renda mensal acima de cinco salários mínimos, enquanto uma declarou desconhecer a renda da família. Quanto ao estado marital, nove participantes referiram que moravam com o companheiro enquanto as três que viviam desacompanhadas residiam com os pais.

Do total de participantes, oito submeteram-se a cesariana, devido a complicações maternas que levaram ao sofrimento fetal agudo, e quatro foram submetidas ao parto normal. Em relação à história gestacional anterior, oito mães entrevistadas eram primíparas enquanto quatro eram não-primíparas. Dentre as mães, sete referiram experiência de cuidado prestado a recém-nascidos, porém apenas uma havia cuidado de recém-nascido prematuro. O banho, a troca de roupas e de fraldas e o curativo do coto umbilical foram os procedimentos citados.

Com relação ao peso de nascimento dos recém-nascidos, sete bebês classificaram-se como de baixo peso ao nascer, quatro como de muito baixo peso, e um bebê foi classificado como de extremo baixo peso. A idade gestacional ao nascimento foi avaliada por duas escalas de classificação: Método de Capurro e Nova Escala de Ballard (New Ballard Score); esta é usada para avaliar os recém-nascidos prematuros extremos. Pelo exame do Capurro somático, realizado pelo neonatologista após o nascimento, observou-se que a idade gestacional de nove bebês variou de 31 a 35 semanas e 6/7. Os três bebês, avaliados pela classificação do New Ballard Score, mostraram idade gestacional com variação entre 29 semanas e 6/7 e 30 semanas.

Quanto ao tempo de permanência na Unidade de Terapia Intensiva Neonatal, verificou-se que três bebês prematuros ficaram internados nesta unidade por um período de até 10 dias, quatro permaneceram entre 11 e 20 dias, um permaneceu por
30 dias e dois mantiveram-se internados por um período acima de 31 dias. Apenas dois recém-nascidos não necessitaram de internação na Unidade de Terapia Intensiva Neonatal, permanecendo todo o período de internação na Unidade Semi-Intensiva. Nesta, três bebês prematuros permaneceram até dez dias, sete entre 11 e 20 dias, um por 30 dias, e um manteve-se internado por mais de 31 dias.

Dentre as mães, dez permaneceram na Unidade Canguru por período que variou entre um e sete dias, enquanto uma permaneceu um dia na Casa de Apoio, por falta de vaga na Unidade Canguru, e duas mães não permaneceram nestas unidades. No momento da alta, um bebê prematuro tinha diagnóstico de hidrocefalia discreta e dois doença do refluxo gastroesofágico. Conforme registros, os demais saíram de alta hospitalar aparentemente sem intercorrências.

\section{Caracterização da moradia}

Os dados apontaram que oito mães viviam em moradia própria, enquanto quatro moravam em casa alugada. No perfil dos domicílios, verificou-se que a totalidade das participantes referiu construção de alvenaria, coleta pública de lixo domiciliar e sistema de esgoto e energia elétrica de rede pública; uma mãe referiu utilizar água proveniente de poço artesanal, e as demais faziam uso da rede pública.

Vivência da mãe no cuidado do bebê prematuro, no domicílio

O tratamento dos dados obtidos com a questão aberta gerou a construção de oito Discursos do Sujeito Coletivo, dos quais, para este texto, selecionaram-se três (números 2, 5 e 7) conforme segue.

\section{Reproduzindo o que aprendeu na unidade neonatal}

A forma como as enfermeiras ensinam a gente aqui [hospital], você não tem dificuldade nenhuma em casa. Só se você não tiver vontade de aprender. Do contrário, elas ensinam bem. Todas as orientações que eu recebi aqui no hospital eu tento fazer em casa com o bebê, tudo do mesmo jeito. Eu cuidava aqui né, a enfermeira deixava eu cuidar, mas não é a mesma coisa, em casa eu tô me sentindo mais mãe. Aqui eu também me sentia, mas ficava assim meio tímida, porque elas ficavam olhando se eu estava fazendo certinho ou não. Mas em casa você já fica, mais assim, porque é só você. Você troca do mesmo jeito que elas ensinaram aqui.[...] Eu não perco nada do que aprendi aqui no hospital. [...] Cada dia que eu vejo ele engordando uns cinco gramas, para mim é uma alegria muito grande. Eu segui o hospital (rotinas de amamentação), de três em três horas. Que era como eu estava fazendo aqui. [...] Tudo o que eu aprendi no hospital eu tô fazendo em casa. Do jeitinho que eles me ensinaram.[...] Aqui eu aprendi. Tá sendo tranqüilo, porque aqui eu já estava fazendo isso. [...] Eu prestava atenção como era aqui e eu tô tentando cuidar. Eu faço tudo o que eu fazia aqui, quando eu fiquei no canguru. Aqui no hospital eles deixam a gente preparada, para o que vai passar em casa. Eu aprendi muita coisa, sabe. De como cuidar do bebê, as enfermeiras são muito boas. Em casa, eu não tô tendo problema nenhum. (DSC.2) 


\section{Recebendo ajuda dos familiares}

Minha família é bem, assim, unida. Minha mãe veio ficar comigo. Mas ele [bebê] tem todo o carinho, que minha mãe, meus irmãos, ficam o dia inteiro com ele. Não sei se é porque minha mãe veio para me ajudar, mas não estou tendo problema em cuidar dele. Assim, dificuldade não. Eu só tô achando meio complicado de madrugada, de ter que acordar de madrugada. Mas dificuldade não, porque eu também tenho minha avó que está me ajudando bastante, né. Então dificuldade mesmo eu não tô tendo não. O pai dele chega do serviço e fica junto com o nenê. O pai dá banho, quando estou atrasada, tipo, no final de semana quando ele não trabalha, se eu estou muito atrasada ele cuida do nenê, dá banho. Para dar a medicação é o meu esposo, eu seguro a boquinha e ele vai pingando as gotinhas. (DSC.5)

\section{Citando a Cartilha da Unidade Neonatal}

No primeiro dia eu liguei aqui (hospital) porque eu achei que ele [bebê] estava tendo diarréia, mas a pediatra falou que era normal. Como ele tava mamando bem, então era normal fazer fezes do jeito que ele tava fazendo, muito! Achei que ele tava com diarréia, mas nem cheguei a pegar a cartilha, liguei para cá. Quando eu queria saber das cólicas, e de tomar banho de sol, lá [na cartilha] eu encontrei, mas sinceramente eu não li tudo não, eu li uns pedacinhos, assim de lavagem de roupas, dessas coisas, mas pro resto não usei não.[...] Eu não tive ainda tempo de pegar [a cartilha]. O que tem lá eu já sei, então nada que tá escrito lá é segredo para mim. Mas não li a cartilha, nem deu tempo, nem precisou. Nem precisei olhar, alguma dica aí, porque tudo o que aprendi aqui (hospital) para mim serviu em casa. (DSC.7)

\section{DISCUSSÃO}

A capacitação da mãe para o cuidado do prematuro, no domicílio, deve ocorrer durante todo o período de sua internação e deve se iniciar logo na admissão do mesmo na unidade neonatal(8). É durante o período de internação que se estabelece a possibilidade de desenvolvimento de habilidades e de conhecimentos específicos, pelos pais, para o cuidado do bebê, no domicílio.

Deve-se considerar que o meio ideal de preparo da mãe para o cuidado do recém-nascido prematuro, no domicílio, é aquele onde a postura do profissional que atende o binômio permite a expressão de necessidades maternas e exclui atitudes que inibem suas manifestações de insegurança. Para um bom desempenho materno, deve ser dada ênfase à participação da mãe e ao seu envolvimento ativo no cuidado da criança ${ }^{(9-11)}$.

Estudo realizado com mães de recém-nascidos prematuros, em São Carlos-SP, analisou as dificuldades verbalizadas pelas mães, no cuidado domiciliar dos filhos, e evidenciou que o manuseio do bebê durante o banho e a troca de roupas e de fralda foram mencionados por todas as mães participantes do estudo como a primeira dificuldade no cuidado domiciliar do prematuro. A justificativa relacionada a estas dificuldades de manuseio relacionou-se ao tamanho reduzido e à fragilidade do bebê, além do sentimento de insegurança para desenvolver o cuidado sem prejuízos para o filho(4).

O ganho de peso apontado no DSC.2 mostra a satisfação materna com o desenvolvimento da criança. Esta situação é concorde com estudo realizado com sete mães de crianças prematuras egressas de um hospital de Feira de Santana, BA, que verificou que essas mulheres se preocupam com o crescimento da criança e este é avaliado, principalmente, pelo ganho de peso, ainda que não seja o esperado ${ }^{(10)}$. Devemos considerar, também, que as mães acreditam que o prematuro é frágil e susceptível a intercorrências.

Quando o tema se relaciona à amamentação, há que se ressaltar a importância do papel do profissional de enfermagem como facilitador de sua promoção ainda no ambiente hospitalar. Chama atenção a necessidade de se valorizar as dificuldades vivenciadas pelas mães para o início e a manutenção da produção adequada de leite. As orientações dos profissionais devem ser feitas diariamente, respeitando as dúvidas e as histórias de cada binômio mãe-bebê prematuro(12).

Vale considerar que o enfermeiro, nas ações educativas, deve "respeitar o saber dos usuários" e reconhecer que o conhecimento profissional - técnico-científico - não é o único que merece valorização no processo do cuidado. O senso comum permeia esse processo e mostra-se cheio de contradições, incertezas e limites, que devem ser reconhecidos pelo profissional na elaboração do planejamento de cuidado pós-alta do recém-nascido prematuro ${ }^{(10-11)}$.

Nesse aspecto, estudo realizado em Sobral-CE, com dinâmicas de grupo realizadas com puérperas com recém-nascido internado, verificou que propiciar atividades em grupos formados por mães favorece o contato da díade mãe-profissional de enfermagem, e estimula a integração entre ambos e a adaptação à condição de ter um filho internado ${ }^{(13)}$.

O processo de preparo para alta do recém-nascido prematuro egresso da Unidade Neonatal deve considerar, ainda, o acompanhamento do prematuro e de sua família após a alta, no domicílio, com visitas domiciliares frequentes. Também é indicada consulta de retorno ao serviço de atenção primária já na primeira semana, pois esta se caracteriza por um período crítico de adaptação da criança para com os familiares e dos cuidados prestados a ela pelos pais ${ }^{(14)}$.

Verificou-se que a Unidade Neonatal onde este estudo foi realizado demonstrou atender as necessidades maternas de capacitação para o cuidado do prematuro, no domicílio. Nesse sentido, estudo citado anteriormente aponta para a importância da capacitação materna como preparo para o cuidado do recém-nascido prematuro no domicílio, o que reduz a ansiedade e aumenta sua autoconfiança no cuidar, e facilita a adaptação da família à criança, após a alta hospitalar. Sugere, também, o seguimento com primeira consulta na primeira semana, no domicílio, para avaliar adaptação no $\operatorname{lar}^{(10)}$.

Estudo de revisão bibliográfica sobre preparo de pais de recém-nascido prematuro para sua alta hospitalar destacou que os profissionais de enfermagem devem enfatizar medidas que estimulem a criação de vínculo, entre os pais e o recém-nascido prematuro, ainda na unidade neonatal, o que é facilitado pela sua inserção na unidade e participação na 
elaboração de um plano de alta da criança. Cabe ao profissional construir estas estratégias de estímulo por meio de reforço de orientações sobre as condições da criança, estímulo para o contato pele-a-pele mãe-prematuro e incentivo à visita de familiares do bebê à unidade neonatal. O estímulo ao vínculo favorece o envolvimento de redes de apoio informal - um dos principais suportes para os pais após a alta hospitalar ${ }^{(15)}$.

Sob esse enfoque, emergiu dos relatos o apoio dos familiares à mãe do bebê prematuro. Este suporte contribuiu para minimizar as dificuldades decorrentes das necessidades maternas inerentes ao cuidado do bebê, caracterizadas pela sua adaptação ao novo ambiente. O convívio, no domicílio, com o egresso da unidade neonatal, também, é vivenciado como um processo de adaptação dos pais. Por isso faz-se necessária uma rede de apoio informal nesta transição hospital-domicílio.

Sabe-se que o espaço domiciliar proporciona um terreno fértil para a formação de redes de apoio e de solidarieda$\mathrm{de}^{(16)}$. Estas redes são constituídas pelo apoio formal onde estão inseridos os profissionais de saúde, e pelo apoio informal, constituído pelos familiares, amigos e religiosos ${ }^{(4,17)}$.

Estudo realizado em Passo Fundo, RS, com 14 mães de prematuros residentes na zona urbana, mostrou que ao buscar informações sobre o cuidado do filho, no domicílio, essas mães deram preferência aos familiares, em detrimento dos profissionais, o que demonstrou a valorização do suporte familiar no cuidado da criança ${ }^{(18)}$. Tal fato também pode ser observado neste estudo quando a procura por ajuda profissional restringiu-se a situações desconhecidas pela mãe, que poderiam implicar em danos à saúde do bebê. Essa situação concorda com o estudo anteriormente citado (18), e ambos refletem a importância do equilíbrio entre apoio formal e informal para a segurança materna no cuidado do prematuro, no domicílio.

Nesse sentido, o profissional de saúde deve atuar junto à unidade familiar, verificando suas demandas e necessidades desde o primeiro encontro na internação do recém-nascido prematuro até a estruturação de sua assistência na unidade neonatal. A família deve ser vista como o núcleo de cuidados, uma vez que se insere em um sistema de relações sociais, de ligação afetiva duradoura e que perpetua a relação de cuidado dentro de um processo histórico ${ }^{(17)}$.

Assim, concorda-se com os resultados do estudo realizado na cidade de Ribeirão Preto-SP(9) ${ }^{(9)}$ em que se identificou a importância da inserção da família do recém-nascido prematuro nos programas educativos promovidos pela unidade neonatal. De modo geral, os serviços dão prioridade às mães, mas se incorporarem os familiares, enriquecerão discussões em grupos com a possibilidade de revisão de hábitos e valores da cultura familiar e a troca de experiência entre seus membros, o que favorece mudanças de atitudes voltadas à saúde e ao bem-estar da criança e de toda a família. A inserção de familiares durante os cuidados do recém-nascido prematuro, na internação, também, deve ser contemplada no plano de cuidados de enfermagem para possibilitar o auxílio da mãe no cuidado do filho, no domicílio.

Os dados que emergiram nos Discursos do Sujeito Coletivo também levam à constatação que, apesar dos sentimentos de medo e de insegurança no desempenho de alguns cuidados básicos com o recém-nascido prematuro, a ajuda do companheiro no compartilhamento do cuidado, no domicílio, contribuiu para a segurança materna no cuidado do bebê. A inserção gradativa dos pais no papel de cuidadores pode ser estabelecida ainda na unidade neonatal, para que tanto os profissionais como os pais possam identificar as necessidades de aprendizagem e de adaptação no preparo para o cuidado domiciliar do filho nascido prematuro.

Por outro lado, a Cartilha de orientações se constitui em um dos recursos utilizados por alguns serviços para orientação da alta hospitalar do prematuro. É um material didático-pedagógico que se insere na estrutura de planejamento de alta e que compreende um instrumento que favorece o processo de educação em saúde. Cabe lembrar que o instrumento de orientações utilizado pelo hospital, campo do estudo, caracteriza-se como uma Cartilha e foi elaborado pelos profissionais de enfermagem, constituindo-se por informações relacionadas ao cuidado do bebê no domicílio. Quando há necessidade de orientações para o cuidado diante de intercorrências ou patologias, estas são informadas em materiais específicos.

As atividades de educação em saúde estabelecidas por meio de material impresso visam instrumentalizar os pais para sua inserção no processo assistencial e no desenvolvimento de habilidades para o cuidado domiciliar da criança. Vale ressaltar que a educação em saúde não é apenas uma prática pedagógica, mas uma prática social que permite ao sujeito que a recebe refletir sobre seu papel no contexto em que se insere ${ }^{(8)}$.

Os dados obtidos mostraram que as mães buscaram orientação diretamente do profissional para esclarecimento de dúvidas surgidas no domicílio. Este fato não subestima o valor pedagógico da Cartilha, que, embora não utilizada integralmente, foi consultada para esclarecimento de dúvidas específicas. Nessa condição, a Cartilha tem função de apoio materno para consulta, diante de situações que não requerem solução imediata.

Estudo realizado com 38 mães de recém-nascido prematuro, na cidade de Ribeirão Preto, SP, se constituiu de reuniões de grupos com discussões sobre o conteúdo de uma cartilha, elaborada com a participação materna e voltada ao cuidado da criança com vistas ao preparo para a alta, verificou que as mães apontaram a cartilha como meio importante de educação em saúde voltada aos familiares, pois poderiam se valer das orientações nela contidas para abordar familiares que apresentassem comportamentos destoantes do esperado no contato com o recém-nascido prematuro, e que poderiam ser prejudiciais. A cartilha seria empregada como reforço das afirmações maternas sobre o cuidado com o bebê. Seria empregada como um meio de socializar com a família o conhecimento adquirido no cuidado de uma criança prematura $^{(9)}$. No mesmo estudo, as mães, também, avaliaram que a cartilha é um material relevante para sua atuação, no domicílio, pois possibilita consultas e direciona o cuidado do recém-nascido prematuro ${ }^{(9)}$. 


\section{CONCLUSÕES}

A dinâmica de preparo da mãe para o cuidado do filho prematuro, na Unidade Neonatal, é favorecida pela atuação dos profissionais de enfermagem envolvidos em sua assistência, e é reconhecida pelas mulheres como facilitadora de sua capacitação para cuidar do bebê prematuro, no domicílio, trazendo-lhe segurança no desempenho do papel de cuidadora e favorecendo sua adaptação às necessidades do recém-nascido prematuro.

Verifica-se, também, que o suporte dado pelos familiares à mãe torna-se um fator diferenciador para seu auxílio, uma vez que o apoio recebido contribui para minimizar as dificuldades na atenção às necessidades do bebê prematuro e gera o compartilhamento de sentimentos de satisfação pela presença concreta do filho, no domicílio. O apoio e o envolvimento oferecidos à mãe do prematuro pelos familiares confirmam a indispensabilidade de sua inserção cada vez mais iminente no planejamento de alta hospitalar na unidade neonatal.

Por sua vez, o modelo de orientações fornecido pelo hospital onde o estudo foi realizado oferece como suporte uma Cartilha de informações, além das orientações contínuas em campo clínico. A Cartilha distribuída como instrumento de apoio e dirigida aos familiares de todos os recém-nascidos propicia a consulta que, neste estudo, foi realizada ocasionalmente pela mãe, no domicílio; ainda que a Cartilha se mostre satisfatória para esclarecer dúvidas.

A satisfação materna ao prestar cuidados ao filho prematuro, no domicílio, associada à segurança ao assisti-lo e ao apoio recebido de familiares e profissionais, indicam as condições de atendimento do binômio mãe/família-recém-nascido prematuro, na unidade neonatal onde o estudo foi realizado.

Por outro lado, os achados reforçam a importância da ênfase que deve ser dada ao preparo do familiar para a alta hospitalar do prematuro, uma vez que exerce importante papel de apoio materno. Demonstrar e orientar o cuidado, de maneira contínua, planejada e gradativa, oferece ao familiar a possibilidade e o tempo necessários para adaptar-se às condições do recém-nascido prematuro, no decorrer de seu período de internação na unidade neonatal.

Os resultados obtidos permitem recomendar às unidades neonatais que invistam na inserção de múltiplas estratégias para a capacitação e o envolvimento materno e familiar no plano de cuidado do recém-nascido prematuro, que deve ser iniciado na internação, e ter como metas o preparo para alta e a continuidade do cuidado no domicílio, para neutralizar agravos à sua saúde.

\section{REFERÊNCIAS}

1. Rugolo LMSS. Crescimento e desenvolvimento a longo prazo do prematuro extremo. J Pediatr 2005; 81(1supl 1):S101-10.

2. Ministério da Saúde (Brasil), Secretaria de Atenção à Saúde. Departamento de Ações Programáticas e Estratégicas. Atenção à saúde do recém-nascido: guia para profissionais de saúde. Brasília: Ministério da Saúde; 2011.

3. Ministério da Saúde (Brasil), Secretaria de Políticas de Saúde. Área de Saúde da Criança. Atenção humanizada ao recém-nascido de baixo peso: método Mãe Canguru: manual técnico. Brasília: Ministério da Saúde, 2002.

4. Feliciano RAF. Rede de apoio social utilizada pelas mães de bebês prematuros e de baixo peso egressos de uma Unidade de Terapia Intensiva Neonatal no município de São Carlos-SP. Ribeirão Preto. Dissertação [Mestrado em Enfermagem] - Escola de Enfermagem de Ribeirão Preto, Universidade de São Paulo; 1999.

5. Fontanella BJB, Ricas J, Turato ER. Amostragem por saturação em pesquisas qualitativas em saúde: contribuições teóricas. Cad Saúde Pública 2008;24(1):17-27.

6. Pursley DM, Cloherty JP. Avaliação do recém-nascido: identificando o recém-nascido de alto risco e avaliando idade gestacional, prematuridade, pós-maturidade e os recém-nascidos grandes para a idade gestacional e os pequenos para a idade gestacional. In: Cloherty JP, Stark AR. Manual de neonatologia. Rio de Janeiro: Medsi; 2000.p.32-54.
7. Lefèvre $\mathrm{F}$, Lefèvre $\mathrm{AMC}$. O Discurso do Sujeito Coletivo: um novo enfoque em pesquisa qualitativa (desdobramentos). Caxias do Sul: EDUCS; 2003.

8. Fonseca LMM, Scochi CGS, Mello DF. Educação em saúde de puérperas em alojamento conjunto neonatal: aquisição de conhecimento mediado pelo uso de um jogo educativo. Rev Latinoam Enferm 2002;10(2):166-71.

9. Ferecini GM, Fonseca LMM, Leite AM, Daré MF, Assis CS, Scochi CGS. Percepções de mães de prematuros acerca da vivência em um programa educativo. Acta Paul Enferm 2009;22(3):250-6.

10. Morais AC, Quirino MD, Almeida MS. O cuidado da criança prematura no domicílio. Acta Paul Enferm 2009;22(1):24-30.

11. Tronco CS, Padoin SMM, Neves ET, Landerdahl MC. Cuidado domiciliar de recém-nascidos egressos da Terapia Intensiva: percepção de familiares. Rev Enferm UERJ 2010;18(1):108-13.

12. Isaacson LJ. Steps to successfully breastfeed the premature infant. Neonatal Netw 2006;25(2):77-86.

13. Monteiro MAA, Pinheiro AKB, Souza AMA. Grupo de apoio: relações interpessoais entre puérperas com filhos recém-nascidos hospitalizados. Acta Paul Enferm 2008; 21(2):287-93.

14. Vieira CS, Mello DF. O seguimento da saúde da criança pré-termo e de baixo peso egressa de terapia intensiva neonatal. Texto \& Contexto Enferm 2009;18(1):74-82. 
15. Couto FF, Praça NS. Preparo dos pais de recém-nascido prematuro para alta hospitalar: uma revisão bibliográfica. Esc Anna Nery Rev Enferm 2009;13(4):886-91.

16. Lopes TC, Mota JAC, Coelho S. Perspectives from a home based neonatal care program in Brazil's Single Health System. Rev Latinoam Enferm 2007;15(4):543-8.

17. Gomes MMF. As repercussões familiares da hospitalização do recém-nascido na UTI Neonatal: construindo possibilidades de cuidado. São Paulo. Tese [Doutorado] - Escola de Enfermagem, Universidade Federal de São Paulo; 1999.

18. Simioni AS, Geib LTC. Percepção materna quanto ao apoio social recebido no cuidado às crianças prematuras no domicílio. Rev Bras Enferm 2008;61(5):645-51. 